\title{
Selected topics in diabetes
}

\author{
R D G LESLIE
}

The management of diabetes has been transformed in recent years. Evidence that hyperglycaemia influences susceptibility to diabetic complications has stimulated efforts to obtain optimal control. Today the person with diabetes measures his own blood glucose concentration, eats fibre, wears pumps, and injects human insulin. His physician speaks of type 1 and type 2 diabetes, single point mutations, and receptor downregulation. In a specialty such as this regular reviews are essential.

Recent Advances in Diabetes is aimed at the specialist in diabetes. It is well presented and extremely well illustrated. The authors, British and American in the main, write clearly and with authority. Since many of the advances in diabetes stem from basic research it is entirely appropriate to find space devoted to topics that are essentially scientific. Here you will learn of the wonders of insulin-its complex anatomy and limited domains. These are the domains which interact on the cell surface with insulin receptors. Insulin receptors attract much attention, though their role in the pathogenesis of type 2 diabetes is not clear. Presented as the knave, they may yet turn out to be the joker, for their numbers are decreased under many diverse circumstances.

For those of a more clinical bent there is an excellent discussion of diabetic pregnancy. At present, the pregnant woman with diabetes need fear only macrosomia and congenital malformations; and the latter may possibly be prevented by excellent diabetic control at the time of conception and in the first trimester.

How can we obtain optimal diabetic control? No question is more important and no answer more uncertain. Many exciting methods are under investigation. Peritoneal insulin, hepatic specific insulin analogues, and pancreatic transplantation promise much for the future. But at present the choice lies between conventional multiple insulin injections and subcutaneous infusions by pump, each supplemented by new techniques for estimating control. These insulin delivery systems have been championed with religious fervour. It is a pleasure, therefore, to read a balanced account of the relative merits of both by protagonists of each. Such is the strength of research into diabetes that one may recommend several other chapters for their exciting and novel approach. They cover a wide range and include diabetic neuropathy, the enteroinsular axis, fatty acid mobilisation, and glucose counterregulation.

If the other subjects were dealt with in such detail then this book would be essential reading. But of 20 subjects, only half are covered comprehensively. The remainder are presented in such broad outline that the specialist will find them of little interest. Many contain references no later than 1981. Thus, some sections are out of date, and irritating omissions result. In a brief review of protein glycosylation there was nothing on rapid reversible glycosylation and little on the relative value of measuring glycosylated haemoglobin and glycosylated proteins. A detailed account of the cause of type 1 diabetes does not mention pituitary antibodies, activated lymphocytes, $64 \mathrm{~K}$ proteins, and HLA DR 3 and 4 subtypes.

As ever, scientists move faster than publishers. This much one can forgive, but one cannot so easily excuse the idiosyncratic selection of subjects. Diabetic ketoacidosis, behavioural development, and platelets are not subjects where one can readily detect important recent advances. Their inclusion makes one all the more aware that no space has been found for the insulin gene, abnormal insulins, or glucose clamps. Thus the articles are of variable quality-from the very best, requiring careful study, to the most superficial, deserving only a cursory glance. Eclectic and expensive, it is the sort of book that is best found on the shelf of someone else's library. Don't buy it-borrow it.

Recent Advances in Diabetes. No 1. Ed Malcolm Nattrass and Julio V Santiago. (Pp 258; £19·50.) Churchill Livingstone. 1983.

\section{Contributors}

GEORGE DUNEA is chairman of the division of nephrology and hypertension at Cook County Hospital, Chicago, Illinois.

W K Cowan is consultant pathologist to the Gateshead area hospitals and honorary lecturer at the University of Newcastle upon Tyne.

L J BRUCE-CHWATT, emeritus professor of tropical hygiene at the University of London, now works at the Wellcome Museum of Medical Science in London.

ELIZABETH A BRAIN is medical editor and coordinator for learning resources, Faculty of Health Sciences, McMaster University, Hamilton, Ontario, Canada.

DOUGLAS GAIRDNER is a retired consultant paediatrician and editor of Cruising Association Bulletin.
$\mathrm{K}$ B Thоmas is a general practitioner in Southampton.

GWENETH WHITTERIDGE was formerly lecturer in the History of Medicine, University of Edinburgh.

DAvid DE BONO is a consultant cardiologist at the Royal Infirmary, Edinburgh and part time senior lecturer in the department of medicine, University of Edinburgh.

MichaEl N MARSH is senior lecturer in medicine at the University of Manchester.

J A BLACK is an honorary consultant paediatrician at King's College Hospital, London.

R D G LesLie is a Wellcome Trust senior fellow and a consultant physician at King's College Hospital, London. 